\title{
Longitudinal associations between conflict monitoring and emergent academic skills: An event-related potentials study
}

\author{
Elif Isbell $^{1}$ (D) Susan D. Calkins ${ }^{2}$ (D) | Veronica T. Cole $^{3} \mid$ Margaret M. Swingler $^{4}$ \\ Esther M. Leerkes ${ }^{2}$
}

\begin{abstract}
${ }^{1}$ Department of Psychology, University of Michigan, Ann Arbor, Michigan

${ }^{2}$ Department of Human Development and Family Studies, University of North Carolina at Greensboro, Greensboro, North Carolina

${ }^{3}$ Center for Developmental

Science, University of North Carolina at Chapel Hill, Chapel Hill, North Carolina

${ }^{4}$ Frank Porter Graham Child Development Institute, University of North Carolina at Chapel Hill, Chapel Hill, North Carolina

\section{Correspondence}

Elif Isbell, Department of Psychology, University of Michigan, Ann Arbor, MI.

Email: eisbell@umich.edu

Funding information

Eunice Kennedy Shriver National Institute of Child Health and Human Development, Grant/Award Number: 5R01HD071957
\end{abstract}

\begin{abstract}
Identifying the links between specific cognitive functions and emergent academic skills can help determine pathways to support both early academic performance and later academic achievement. Here, we investigated the longitudinal associations between a key aspect of cognitive control, conflict monitoring, and emergent academic skills from preschool through first grade, in a large sample of socioeconomically diverse children $(N=261)$. We recorded event-related potentials (ERPs) during a Go/ No-Go task. The neural index of conflict monitoring, $\Delta \mathrm{N} 2$, was defined as larger N2 mean amplitudes for No-Go versus Go trials. $\Delta \mathrm{N} 2$ was observed over the right hemisphere across time points and showed developmental stability. Cross-lagged panel models revealed prospective links from $\Delta \mathrm{N} 2$ to later math performance, but not reading performance. Specifically, larger $\Delta \mathrm{N} 2$ at preschool predicted higher kindergarten math performance, and larger $\Delta \mathrm{N} 2$ at kindergarten predicted higher firstgrade math performance, above and beyond the behavioral performance in the Go/ No-Go task. Early academic skills did not predict later $\Delta \mathrm{N} 2$. These findings provided electrophysiological evidence for the contribution of conflict monitoring abilities to emergent math skills. In addition, our findings suggested that neural indices of cognitive control can provide additional information in predicting emergent math skills, above and beyond behavioral task performance.
\end{abstract}

\section{KEYWORDS}

conflict monitoring, emergent math and reading skills, event-related potentials, Go/No-Go, $\Delta \mathrm{N} 2$

\section{1 | INTRODUCTION}

It has been well established that emergent math and reading skills at preschool and during the first years of formal schooling set the stage for later academic competence (Duncan et al., 2007; Jordan, Kaplan, Ramineni, \& Locuniak, 2009; Watts et al., 2015). Pinpointing how and when specific cognitive functions contribute to emergent academic skills can inform curriculum development and training designs, which in turn can have implications for supporting both early academic performance and later academic achievement. A growing number of studies have demonstrated the contributions of various aspects of cognitive control, such as the ability to hold multiple items in mind or to switch flexibly between task rules, to emergent academic skills (e.g., Bull, Espy, \& Wiebe, 2008; Fuhs, Nesbitt, Farran, \& Dong, 2014; Purpura, Schmitt, \& Ganley, 2017). However, there is still a paucity of information regarding the extent to which a core component of cognitive control, conflict monitoring, is linked to emergent academic skills.

According to the conflict monitoring theory, when incompatible response representations are activated, conflict arises (Botvinick, Braver, Barch, Carter, \& Cohen, 2001). A common occurrence of such incompatibility is when a response that has 
become automatic-but is incongruent with the task goal-competes with a less rehearsed response that is relevant for the task (Nieuwenhuis, Yeung, Wildenberg, \& Ridderinkhof, 2004; Randall $\&$ Smith, 2011). Successful monitoring of this type of response conflict may contribute to the execution of new academic skills which frequently build on previously acquired skills. The overarching goal of this study was to delineate the longitudinal associations between conflict monitoring and emergent math and reading skills as children transitioned from preschool to the early years of elementary school. In the current study, we used a neural index of conflict monitoring to address four specific aims. First, we examined the longitudinal characteristics of an ERP index of conflict monitoring, $\Delta N 2$, across three time points spanning from preschool to kindergarten and first grade. Second, we investigated the prospective links from $\Delta \mathrm{N} 2$ to later math and reading skills. Third, we evaluated whether $\Delta \mathrm{N} 2$ could provide additional information in predicting emergent academic skills above and beyond the behavioral performance during the task in which $\Delta \mathrm{N} 2$ was measured. Fourth, we assessed whether the associations between $\Delta \mathrm{N} 2$ and emergent academic skills were bidirectional such that there were also prospective links from emergent academic skills to later $\Delta \mathrm{N} 2$.

\subsection{A neural index of conflict monitoring}

It has been argued that cognitive control entails not only a regulatory component that exerts influence on information processing and behavior, but also an evaluative component that monitors the occurrence of conflicts (Botvinick et al., 2001; Botvinick, Cohen, \& Carter, 2004; Carter \& van Veen, 2007). This evaluative dimension, which is referred to as conflict monitoring, first assesses levels of conflict. Then, it passes this information on to the regulatory systems of control, triggering these systems to adjust the strength of their influence on information processing and behavior. As such, conflict monitoring is involved in determining to what extent cognitive control will be recruited, how the influence of relevant cognitive control processes will be modulated or optimized in guiding task performance, and how and when control can be withdrawn without deterring task performance (Botvinick et al., 2001; Kool, Shenhav, \& Botvinick, 2017).

One common occurrence of conflict is the activation of incompatible representations of automatic responses that are not relevant for the task and less rehearsed, but task-relevant, responses (Botvinick et al., 2001). Monitoring this type of response conflict may be particularly important when children are transitioning from using a well-rehearsed response rule to a new one as they acquire new academic skills. Although a preceding skill can provide the foundation for a new one, it can also create a conflict between responses matching the previously acquired skill versus responses relevant for the application of the new skill. It is plausible that children who have stronger conflict monitoring systems are less prone to using prepotent but irrelevant responses and would perform better in academic tasks as they acquire new skills.
One obstacle to examining the associations between conflict monitoring and emergent math and reading skills is the difficulty of isolating conflict monitoring in behavioral tasks. There are many well-established laboratory tasks that elicit response conflicts, such as the Go/No-Go task in which individuals are instructed to respond to a set of stimuli, while withholding their responses to a particular stimulus (e.g., "push a button each time you see a letter, except for when you see an X"). There, the conflict is elicited between the "respond" and "do not respond" representations (Randall \& Smith, 2011). However, successful performance in this task relies not only on conflict monitoring, but also on several other cognitive processes, such as sustained attention, maintenance of task-relevant goals, activation of task-relevant motor behavior, and inhibition of motor behaviors that interfere with task goals. Therefore, it becomes challenging to separate the contribution of conflict monitoring from other cognitive processes via behavioral measures, such as task accuracy.

To address this challenge, several researchers have utilized event-related potentials (ERPs) to capture a neural index of conflict monitoring (Donkers \& Van Boxtel, 2004; Enriquez-Geppert, Konrad, Pantev, \& Huster, 2010; Jonkman, 2006). Given its high temporal resolution, ERP technique is well suited for investigating cognitive processes that occur relatively rapidly, and enables the study of neural mechanisms involved in specific computational operations. An ERP component that has been considered to index conflict monitoring is the anterior N2 (Randall \& Smith, 2011). Generally, in a classic Go/No-Go task that includes frequent Go and rare No-Go stimuli, the N2 component is larger (more negative in amplitude) for the No-Go versus Go trials. Given that the task has a motor response inhibition component, several researchers have contended that the amplitude difference between the No-Go versus Go conditions reflects a process specific to the inhibition of a planned response (for a review, see Folstein \& Van Petten, 2008). However, others have argued that the amplitude difference between the N2 component for the No-Go versus Go conditions does not index the inhibition of a motor response per se, but rather the monitoring of conflict in response representations (Nieuwenhuis et al., 2004; Randall \& Smith, 2011). Supporting evidence for this perspective has come from studies in which the trials that required a response (Go) were rare instead of the trials with no response (No-Go) (Donkers \& Van Boxtel, 2004; Enriquez-Geppert et al., 2010; Lucci, Berchicci, Perri, Spinelli, \& Di Russo, 2016). In these studies, the N2 component was larger for the infrequent responses compared to the frequent responses, regardless of whether the infrequent trials required a motor response or not. Such findings suggest that the difference in N2 amplitude between No-Go and Go trials depends on which response condition is infrequent, and reflects the monitoring of conflict between competing response representations.

\subsection{Characteristics of $\Delta \mathrm{N} 2$ in early childhood}

In the present study, we used this $\Delta \mathrm{N} 2$ measure (i.e., the difference in ERP amplitudes between the No-Go and Go conditions) as a neural 
index of conflict monitoring to investigate the longitudinal associations between conflict monitoring and emergent math and reading skills from preschool through first grade. To do so, we first focused on delineating the characteristics of the N2 component in a classic Go/No-Go task (frequent Go trials vs. infrequent No-Go trials) in our sample across this developmental period. A common limitation of previous research was the predominant use of cross-sectional designs in studying the development of N2 component (for reviews, see Hoyniak, 2017; Lo, 2018). Our study is among the first to examine the developmental characteristics of N2 with a longitudinal design. This step was necessary as previous research findings were inconsistent regarding the predominant scalp distribution and developmental change of the $\mathrm{N} 2$ component in Go/No-Go tasks in this age range. With regard to scalp distribution, several studies focused on medial-central electrode locations to capture the N2 component in Go/No-Go tasks in childhood (Cragg, Fox, Nation, Reid, \& Anderson, 2009; Lamm, Zelazo, \& Lewis, 2006; Ruberry et al., 2017). However, in several studies that analyzed the scalp distribution of the N2 component across hemispheres, the amplitude of the N2 component was larger for the No-Go versus Go trials specifically over the right hemisphere (Benikos \& Johnstone, 2009; Lahat, Todd, Mahy, Lau, \& Zelazo, 2010; Smith, Johnstone, \& Barry, 2004). In addition, contradictory findings were reported regarding developmental change in the N2 component amplitude in Go/No-Go tasks across childhood. Although there have been reports of either increase or no change in N2 amplitude with age (Cragg et al., 2009; Johnstone et al., 2007), two recent meta-analyses concluded that the amplitude of the N2 component decreases linearly with age (Hoyniak, 2017; Lo, 2018). Such discrepancies in the literature precluded us from having a priori hypotheses about the longitudinal characteristics of the $\Delta \mathrm{N} 2$. This necessitated an examination of where over the scalp $\Delta \mathrm{N} 2$ could be observed as larger (more negative) N2 amplitude for the infrequent No-Go versus frequent Go trials, indexing conflict monitoring, and whether the scalp distribution or amplitude of the N2 component changed as children transitioned from preschool to kindergarten and first grade.

\section{3 | Conflict monitoring and academic performance}

After identifying the characteristics of $\Delta \mathrm{N} 2$ in our sample, we investigated whether this neural index had prospective links to later academic skills and whether these links varied by academic content area (math vs. reading). To do so, we first examined to what extent $\Delta \mathrm{N} 2$ predicted later math performance. Emergent math skills initially rely on rudimentary subskills such as learning to recognize small sets without counting, learning the verbal counting sequence, and mapping number words and quantities to written symbols (Krajewski \& Schneider, 2009; Purpura, Baroody, \& Lonigan, 2013). As children transition from preschool to formal schooling, they acquire new and more sophisticated skills such as using written numerical notations (e.g., numerals and operation signs) and written algorithms. Although previously learned skills lay the groundwork for the acquisition of new skills, the successful execution of new skills also requires monitoring of conflict between prepotent response representations of previously acquired and more rehearsed rules, versus relevant yet nascent response representations of newer rules. For instance, a typical challenge in the acquisition of basic math skills might occur when a child proceeds to subtraction problems after several weeks of working on addition problems. During the transition from addition to subtraction, the response representations will be more potent for adding two numbers together, instead of subtracting one from the other. Success in this transition requires the detection of instances where conflict between response choices (i.e., addition vs. subtraction) occurs so that regulatory cognitive control mechanisms can be recruited in favor of the relevant subtraction response. It is likely that children who have stronger conflict monitoring systems would detect the conflicts between automatic but irrelevant or less efficient responses versus less accustomed but relevant responses, and would perform better in math as they acquire new skills. Therefore, we hypothesized that our neural index of conflict monitoring, $\Delta \mathrm{N} 2$, would have concurrent associations with emergent math skills, as well as predict these skills prospectively.

A large body of research linked various aspects of cognitive control, such as attention shifting and working memory, to both emergent math and reading skills (e.g., Bull et al., 2008; Fuhs et al., 2014). However, several studies suggested that the link between cognitive control and emergent academic skills might be stronger for math compared to reading skills (Blair \& Razza, 2007; Schmitt, Geldhof, Purpura, Duncan, \& McClelland, 2017). These findings brought up the question of whether $\Delta \mathrm{N} 2$ would have prospective links to later reading skills as well. Learning to read in English builds on early foundations such as phonemic awareness (i.e., abstracting the relevant phonemic units from the stream of speech) and letter knowledge, and requires the acquisition of the grapheme-morpheme relations, that is, the visual symbols of the written language (graphemes) represent the sounds of the language (phonemes) (for a review, see Castles, Rastle, \& Nation, 2018). While acquiring these alphabetic decoding skills, children also "read" by relying on visual cues, rote learning, or guessing (Ehri, 2017). As children become skilled readers, they gradually rely less on alphabetic decoding and transition to recognizing familiar written words rapidly and automatically, a process referred to as orthographic learning (Castles et al., 2018). It has been argued that although several aspects of cognitive control, such as attentional control and working memory, are critical for reading performance, early reading development may be more heavily reliant on rote memorization compared to math development (Blair, Ursache, Greenberg, \& Vernon-Feagans, 2015). If reading skills are less reliant on the resolution of conflict between previously acquired versus new responses, conflict monitoring would not have concurrent or prospective associations with emergent reading skills. Alternatively, if conflict monitoring was associated with academic performance regardless of content area, then $\Delta \mathrm{N} 2$ would have concurrent and prospective associations with reading performance, similar to what we expected for math performance.

Another specific aim of the present study was to evaluate whether $\Delta \mathrm{N} 2$ would provide any additional value in predicting 
emergent academic skills, above and beyond behavioral performance during the task in which $\Delta \mathrm{N} 2$ was measured. One possibility is that the neural measures would be redundant with behavioral measures, providing only neurobiological correlates of behavior in a given task. In this case, $\Delta \mathrm{N} 2$ would not provide any added predictive value above and beyond the behavioral performance during the Go/No-Go task. However, it is also possible that neural measures can provide information that may not be readily available by examining overall behavioral performance during a task. For instance, in tasks like Go/No-Go, several other cognitive control processes, such as attention and working memory, also contribute to behavioral performance, making it challenging to tease apart the unique characteristics of cognitive faculties like conflict monitoring. Furthermore, in tasks where variability in behavioral performance is low between individuals due to the relative ease of the task, neural measures may provide information about individual differences in underlying neural processes which may be masked by ceiling effects in behavioral performance. To date, a few studies have provided support for the added value of neural measures in predicting academic achievement, above and beyond what could be captured with behavioral measures. For instance, neural activity during a working memory task predicted math performance 2 years later, after taking into account behavioral measures of working memory and reasoning (Dumontheil \& Klingberg, 2011). Hoeft et al. (2007) found that neural measures, comprised of both functional and structural neuroimaging indices, explained additional variance in children's reading performance after taking into account behavioral predictors of reading and language. Similarly, Peters, Meulen, Zanolie, and Crone (2017) reported that neural activity during feedback learning predicted unique variance in reading and math ability over the behavioral testing of feedback learning performance alone. Together, these findings suggested that neural assessments could provide predictive value for academic performance above and beyond behavioral testing alone. Accordingly, it is possible that $\Delta \mathrm{N} 2$ would provide additional information, above and beyond behavioral task performance, in predicting emerging academic skills.

In addition, we tested whether emergent academic skills would also predict conflict monitoring prospectively. A few studies reported bidirectional concurrent and prospective relationships between cognitive control skills and academic performance (Clements, Sarama, \& Germeroth, 2016; Fuhs et al., 2014). With regard to conflict monitoring, as children acquire new academic concepts, they may have greater opportunities to recruit their conflict monitoring system to detect competition between representations of different rules. As such, advancing in academic skills would provide opportunities to practice and get better at conflict monitoring. If this is the case, then math and reading performance would also predict the strength of the neural mechanisms supporting conflict monitoring. It is also possible that such a relationship would emerge especially as children transition to formal schooling and start learning more math and reading rules that potentially conflict with each other.

\section{2 | METHOD}

\section{1 | Participants}

Participants were part of a longitudinal study on school readiness and early academic performance. The initial sample consisted of 278 children from the Southeastern United States, between the ages of 45 and 70 months (Mean $=56, S D=5$ ) at the time of the preschool laboratory visit. Based on parent questionnaires, children were excluded from the current study if their parents reported atypical neuropsychological development at any time point (microcephaly: $n=1$; absence seizures: $n=2$ ). Given reports of the N2 component being altered in individuals with attention-deficit and hyperactivity disorder (Fisher, Aharon-Peretz, \& Pratt, 2011; Shahaf, Fisher, AharonPeretz, \& Pratt, 2015), we also excluded children for whom parents reported diagnosis for ADHD and related medication treatment $(n=14)$. The final analytic sample of the current study consisted of 261 children (55\% female).

To match the diversity of the county from which the children were recruited, we targeted a sample that consisted of $50 \%$ male and 32\% African American (U.S. Census, 2010). According to parent reports, in our final sample, $60 \%$ of children were White, $28 \%$ were African American, $2 \%$ were Asian, and $10 \%$ were multiracial. This sample broadly represented the region from which the children were recruited. For analysis purposes, race and ethnicity information was coded to denote minority status as follows: 0 for non-Hispanic white (not minority; 55\%), 1 for Hispanic White or non-White (minority). The percentages of children who participated in the visits were as follows: $84 \%$ in all visits, $5 \%$ in the preschool and kindergarten visits only, $1 \%$ in the preschool and first-grade visits only, and $10 \%$ in the preschool visit only. Children who participated in all visits did not differ from children who dropped out of the study at kindergarten or first grade in terms of age at the beginning of the study, gender, income-to-needs ratio, or minority status (all ps $>0.15$ ). Twenty-six children included in the current study did not have ERP data at any time point, either for not participating in EEG data collection or due to low data quality (i.e., excessive EEG artifacts). Children without ERP data did not differ from children who had ERP data at any time point in terms of age at the beginning of the study, gender, incometo-needs ratio, or minority status (all ps $>0.28$ ). The covariance coverage is reported in Supporting Information Table S1.

\section{2 | Procedure}

Children were recruited from daycare centers, local community establishments (e.g., parks, libraries, and children's museum), and via participant referral. The study consisted of three waves of data collection, at preschool, kindergarten, and first grade. At the preschool data collection point, none of the children had started kindergarten. The kindergarten laboratory visit took place approximately 1 year after the preschool session and was followed approximately 1 year later by the first-grade visit. At the beginning of each visit, informed consent was obtained from parents or legal guardians (referred to as 
parents) and verbal assent was obtained from the child. Each laboratory visit took approximately $2 \mathrm{hr}$ and consisted of a battery of tasks assessing cognitive development and academic readiness, as well as other tasks of social-cognitive and emotional development. At the completion of each visit, parents received monetary compensation and children selected a small toy.

\section{3 | Measures}

\subsection{1 | Demographics}

Information about children's age, gender, race and ethnicity, and monthly family income was obtained via a questionnaire filled out by parents at the preschool time point. Income-to-needs ratio was used as a proxy for family socioeconomic status. Parents reported family monthly income on an item that consisted of 15 ranges from which to choose (e.g., \$1,000-1,499/month). To compute annual income, the midpoint of each range was used as the measurement of monthly income and was multiplied by 12 . The appropriate poverty threshold was assessed based on the U.S. Census Reports for the year in which annual income was earned, the total number of members in the household, and the number of children living in the home full time. The income-to-needs ratio was computed by dividing the annual family income by the poverty threshold. Descriptive statistics for the demographic variables are presented in Table 1.

\subsection{2 | Emergent academic skills}

To assess emergent math and reading skills, we used the Applied Problems and Letter-Word Identification subscales of the Woodcock-Johnson III Tests of Achievement (Woodcock, McGrew, \& Mather, 2001). In the Applied Problems subtest, children were shown pictorial math problems and instructed to point to or say the answer. This measure is commonly used to assess children's performance in early math operations such as counting, addition, and subtraction. The Letter-Word Identification items involved symbolic learning, matching pictographic representations of words with the actual pictures of objects, and identifying isolated letters and words. In all analyses, standardized scores were used.

\subsection{3 | Conflict monitoring}

A computerized Go/No-Go task (Lahat et al., 2010) was used to capture neural indices of conflict monitoring. The task was presented

TAB LE 1 Descriptive statistics

\begin{tabular}{|c|c|c|c|c|c|}
\hline Variables & $n$ & Min & Max & M & $S D$ \\
\hline \multicolumn{6}{|l|}{ Demographics } \\
\hline $\begin{array}{l}\text { Age in months } \\
\text { (Time 1) }\end{array}$ & 260 & 45 & 70 & 56.36 & 4.70 \\
\hline Percent female & 261 & & & 56 & \\
\hline Percent minority & 261 & & & 45 & \\
\hline $\begin{array}{l}\text { Income-to-needs } \\
\text { ratio }\end{array}$ & 254 & 0.10 & 6.40 & 2.16 & 1.43 \\
\hline \multicolumn{6}{|l|}{$\Delta \mathrm{N} 2(\mu \mathrm{V})$} \\
\hline Preschool & 168 & -16.11 & 8.02 & -4.22 & 4.07 \\
\hline Kindergarten & 171 & -15.83 & 6.42 & -4.42 & 3.63 \\
\hline First grade & 173 & -13.32 & 3.43 & -4.31 & 3.36 \\
\hline \multicolumn{6}{|l|}{ Go/No-Go d' } \\
\hline Preschool & 248 & -0.08 & 5.69 & 2.26 & 1.01 \\
\hline Kindergarten & 228 & 0.79 & 5.39 & 3.00 & 0.89 \\
\hline First grade & 224 & 1.02 & 5.39 & 3.41 & 0.91 \\
\hline \multicolumn{6}{|l|}{ Math performance } \\
\hline Preschool & 261 & 72.00 & 137.00 & 109.65 & 11.61 \\
\hline Kindergarten & 232 & 72.00 & 140.00 & 108.74 & 11.71 \\
\hline First grade & 225 & 82.00 & 139.00 & 107.38 & 11.44 \\
\hline \multicolumn{6}{|l|}{ Reading performance } \\
\hline Preschool & 261 & 70.00 & 140.00 & 105.59 & 11.97 \\
\hline Kindergarten & 232 & 82.00 & 159.00 & 114.36 & 14.88 \\
\hline First grade & 225 & 76.00 & 151.00 & 115.53 & 13.01 \\
\hline
\end{tabular}

Note. $\Delta \mathrm{N} 2$ : neural index of conflict monitoring (mean amplitude of the right hemisphere N2 difference wave); Go/No-Go $d^{\prime}$ : Go/No-Go behavioral performance; Math performance: WoodcockJohnson Applied Problems Standard Scores; Reading performance: Woodcock-Johnson Letter Identification. 


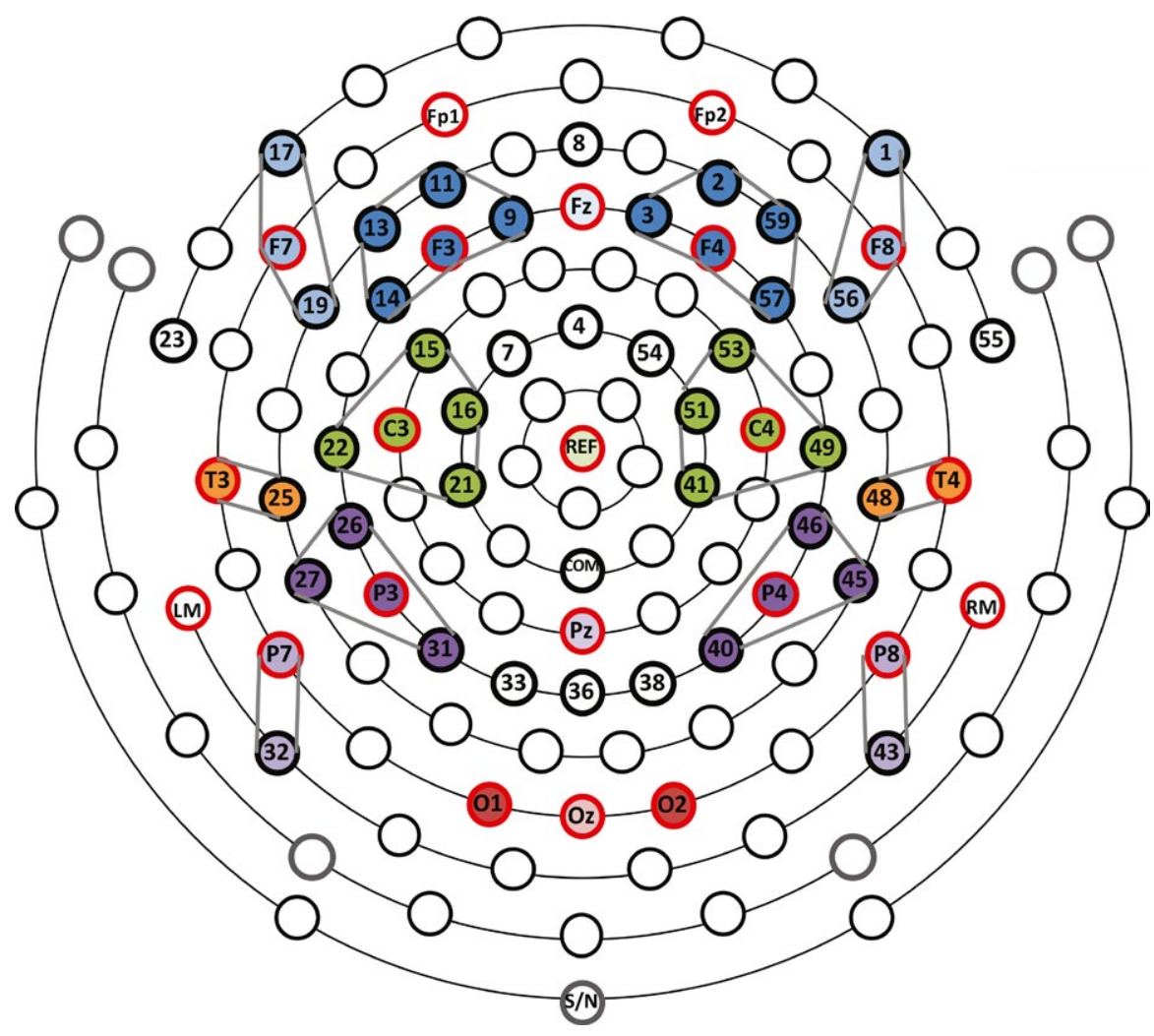

FIGURE 1 64-channel net with 10-20 channels and frontal and central clusters for each hemisphere were identified, following the configuration reported by Vanderwert et al. (2016). A midline cluster, including E8, Fz, and E4 electrodes, was also analyzed via E-Prime version 2.0 (PST, Pittsburgh, PA, USA). Task stimuli included colored animal drawings (cow, horse, bear, pig, or dog). At the beginning of each trial, a fixation point appeared in the middle of the screen. The fixation point was accompanied by a "ding" sound and stayed on the screen for $1,500 \mathrm{~ms}$. This was followed by an animal stimulus, which stayed on the screen either for $1,500 \mathrm{~ms}$ or until a response was registered. Children were instructed to respond by pressing a button as soon as they saw an animal, except for when they saw a dog. A yellow smiley face followed each correct response. A red frowning face followed each incorrect response or a response that occurred after the 1,500 ms stimulus window. Before the task, children completed six Go and four No-Go trials for practice. The practice block was repeated until children responded to at least nine out of 10 trials correctly. All children included in the current study passed the practice. The task consisted of 144 trials (75\% Go, 25\% No-Go), divided into four blocks. Children were offered a break between the blocks. A discriminability index $\left(d^{\prime}\right)$ was calculated as a measure of overall behavioral performance and was calculated as follows: $d^{\prime}=$ Z(Correct/Hit) - Z (Incorrect/False Alarm). Larger values of $d^{\prime}$ indicate greater ability to distinguish signals from noise, and as such, better task performance (Stanislaw \& Todorov, 1999).

\subsection{4 | EEG recording and analyses}

EEG was recorded using a 64-channel HydroCel Geodesic Sensor Net, a NetAmps 300 Amplifier, and the NetStation 4.5.4. software (Electrical Geodesics Inc., Eugene, OR, USA). After a brief warmup period, each child's head circumference was measured and an appropriately sized net was fitted. During the Go/No-Go task, children were seated in front of a computer monitor. The distance and alignment of the monitor were kept consistent across children. To reduce motion artifacts, children were instructed to hold as still as possible during the task. EEG data were sampled at $250 \mathrm{~Hz}$ and referenced online to a single vertex electrode $(\mathrm{Cz})$. Channel impedances were kept at or below $80 \mathrm{k} \Omega$.

EEG preprocessing and ERP analyses were carried out using EEGLAB (Delorme \& Makeig, 2004) and ERPLAB (Lopez-Calderon \& Luck, 2014). EEG data were band-pass filtered from 0.1 to $30 \mathrm{~Hz}$ with a linear finite impulse response (FIR) filter. Following an advisory notice released by EGI on anti-alias filter effects on timing, $8 \mathrm{~ms}$ was added to each original EEG event latency. The configuration of the electrode net is illustrated in Figure 1. Prior to data collection, the sensor nets were customized for the study via the removal of four face electrodes. Electrodes approximating the international 10-20 locations were renamed, and electrode clusters were defined around these standard electrodes as shown in Figure 1 (Vanderwert, Zeanah, Fox, \& Nelson, 2016).

Upon initial inspection of the data, electrodes E23, E29, E47, and E55 were found to be artifact-laden in more than half of the participants and were excluded from further processing. Electrodes E1, FP1, FP2, and E17 were used only for the detection of eye blinks and saccades. For the remaining 52 electrodes, a multistep procedure was followed to replace bad electrodes. First, bad electrodes were detected with the pop_rejchan function in EEGLAB, using a spectrum threshold of 3 SD. The bad electrode detection was conducted on single electrodes instead of clusters for greater precision. Then, via 
visual inspection, additional bad electrodes were noted. Bad electrodes were replaced with the average mean amplitude of the neighboring electrodes within clusters depicted in Figure 1. No more than five electrodes out of 52 (10\%) were replaced per participant. After the bad electrodes were replaced, the EEG data were rereferenced to the average.

The EEG data were epoched offline between $200 \mathrm{~ms}$ prior to and $600 \mathrm{~ms}$ after stimulus onset, using the first $200 \mathrm{~ms}$ as the pre-stimulus onset baseline. This epoch length was consistent with a study that used a Go/No-Go paradigm with a similar age group (Lamm et al., 2014). Artifact rejection was executed using a 200-ms window, moving at $50 \mathrm{~ms}$ increments. To detect eye blinks and saccades, a peak-to-peak rejection threshold of 100 or $125 \mu \mathrm{V}$ was used for electrodes E1, FP1, FP2, and E17. The thresholds were individually adjusted for children upon visual inspection of the epochs marked by ERPLAB. For all other electrodes, the peak-to-peak rejection threshold was $200 \mu \mathrm{V}$. Only correct trials were included in the analyses. ERP data of children who did not have at least 10 artifact-free correct Go and 10 artifact-free correct No-Go trials were excluded from analyses.

To reduce the number of factors used in the statistical analyses, electrode clusters were used instead of single electrodes (Luck \& Gaspelin, 2017). Several studies reported larger N2 mean amplitudes for the No-Go versus the Go trials specifically over the right hemisphere electrodes (Benikos \& Johnstone, 2009; Lahat et al., 2010; Smith et al., 2004). To assess whether similar scalp distributions (i.e., larger N2 for No-Go vs. Go over the right hemisphere) would be observed in our study, frontal-central electrode clusters were created separately for the left hemisphere (averaging the F3 and C3 clusters) and the right hemisphere (averaging the F4 and C4 clusters). For the electrodes included in each cluster, see Figure 1. A midline cluster was also computed by averaging the electrodes Fz, E4, and E8. These electrode clusters were used to extract the mean amplitude measures included in the analyses.

The ERP analyses focused on the mean amplitude of the N2 component measured between 250 and 500 ms poststimulus onset, consistent with the time window selected in a study that used the same paradigm with a similar age group (Lahat et al., 2010). The appropriateness of this time window for the N2 component was confirmed via visual inspection of the grand-average plots for the preschool, kindergarten, and first-grade ERPs. Grand-average ERPs elicited by the No-Go versus Go conditions across the left hemisphere, right hemisphere, and midline anterior and central electrodes included in the analyses are shown in Supporting Information Figures S1, S2, and S3.

Using difference waves eliminates many concurrently active neural processes that do not differ between the trial types being compared (Luck, 2014). Further, this strategy reduces the number of components being analyzed compared to the parent waveforms (e.g., Go N2 and No-Go N2) and provides better estimates of the scalp distribution of the underlying components. Therefore, to isolate the neural processes involved in conflict monitoring, difference waves were used to analyze the associations between the neura index of conflict monitoring, behavioral performance during the Go/ No-Go task, and emergent math and reading skills. Specifically, the ERP index of conflict monitoring was operationalized as the mean amplitude difference between the N2 components for the correct No-Go versus Go trials and was denoted as $\Delta \mathrm{N} 2$.

\section{3 | RESULTS}

\section{1 | Preliminary analyses}

Preliminary analyses were conducted to detect outliers. Scores above or 3.29 SD were considered univariate outliers (Tabachnick \& Fidell, 2007). In fairly large samples (i.e., 100 or more cases), $99.9 \%$ of the $z$-scores lie between -3.29 and +3.29 . A case with an absolute $z$ value of 3.29 or greater is probably an outlier because the likelihood of this case to be sampled from the population of interest is $0.1 \%$ or less. Accordingly, scores above or below 3.29 SD were replaced with the next highest or lowest value. The outlier replacements were made as follows: 1 child for the kindergarten right hemisphere N2 and 1 child for the kindergarten left hemisphere N2; 1 child for the preschool and 1 child for the kindergarten WJ Applied Problems; four children for the preschool, one child for kindergarten, and one child for the first-grade WJ Letter Identification. All analyses were conducted with children's original scores as well as these replaced scores to ensure the results did not depend on the way the outliers were handled. The direction and strength of the results were consistent across these analyses. The results reported here reflect the scores after outlier replacements.

Descriptive statistics are reported in the Supporting Information Table S2 for the number of ERP trials included in the analyses and N2 mean amplitudes for the clusters (midline, left, and right). The initial analyses revealed that there were no differences between N2 mean amplitudes in the Go versus No-Go conditions in the midline cluster, across time points (all $p s>0.125$ ). Therefore, the midline cluster was excluded from further analyses (see Supporting Information Figures S1, S2, and S3).

\section{2 $\Delta$ N2 as a neural index of conflict monitoring}

The longitudinal analyses were conducted with MPlus version 8 (Muthén \& Muthén, 1998-2017). Missing data were handled via full information maximum likelihood (FIML). To examine the N2 mean amplitude difference between conditions (Go vs. No-Go), hemispheres (left vs. right), and time points (preschool, kindergarten, and first grade), a multilevel model was used. Individuals with ERP data for at least one time point were included in this analysis $(N=225)$. $\mathrm{N} 2$ mean amplitude was predicted from condition, hemisphere, and time; all two-way interactions at the within-person level; and age at Time 1, gender, income-to-needs ratio, and minority status at the between-person level.

A model including the three-way interaction between condition, hemisphere, and time was also fit to the data. However, this interaction was not statistically significant and complicated the 
interpretation of the other coefficients; thus, it was excluded from the model. The parameters for the random intercept model (log likelihood $=-5,261.026$; intraclass correlation $=0.242$ ), labeled Model A, are shown in Supporting Information Table S4. No effects were significant at level 2 , indicating that there was no meaningful difference in N2 mean amplitudes across age, gender, income-to-needs ratio, or minority status. At level 1 , there was a significant main effect of hemisphere, and a significant interaction between condition and hemisphere. Because neither of the interaction effects containing time was significantly different from zero, a simpler model omitting these effects was then tested.

The parameter estimates for this model, Model B, are shown in Supporting Information Table S4. In this final model, there were significant main effects of condition and hemisphere, as well as an interaction between them. Probing this interaction indicated that the N2 mean amplitude was larger (more negative) for the No-Go than the Go condition over the right hemisphere (Est. $=-6.211$, $S E=0.292, p<0.001)$. Given that previous research operationalized the neural index of conflict monitoring as larger N2 mean amplitude for the infrequent No-Go responses than frequent Go responses (Randall \& Smith, 2011), this interaction effect represented that the neural index of conflict monitoring, denoted $\Delta \mathrm{N} 2$, was observable over the right hemisphere electrodes (see Supporting Information Figures S1, S2, and S3). Since only the right hemisphere showed the expected pattern for conflict monitoring (larger N2 amplitude for No-Go vs. Go) across time points, only this $\Delta \mathrm{N} 2$ was used in the subsequent analyses. The ERPs averaged over the right hemisphere frontal and central electrodes for the No-Go versus Go trials are shown in Figure 2.

\section{3 | Longitudinal associations between $\Delta \mathrm{N} 2$ and emergent academic skills}

Descriptive statistics and correlations for the control variables, the neural index of conflict monitoring (right hemisphere $\Delta \mathrm{N} 2$ ), Go/NoGo behavioral performance $\left(d^{\prime}\right)$, and emergent academic skills (math and reading) are reported in Tables 1 and 2, respectively. ${ }^{1}$

Cross-lagged panel models (Kenny, 1979; Selig \& Little, 2012) were fit for math and reading subtests to assess the longitudinal associations between $\Delta N 2, d^{\prime}$, and emergent academic skills. Separate cross-lagged panel models were fit for math and reading outcomes (e.g., Fuhs et al., 2014). Each model consisted of autoregressive paths
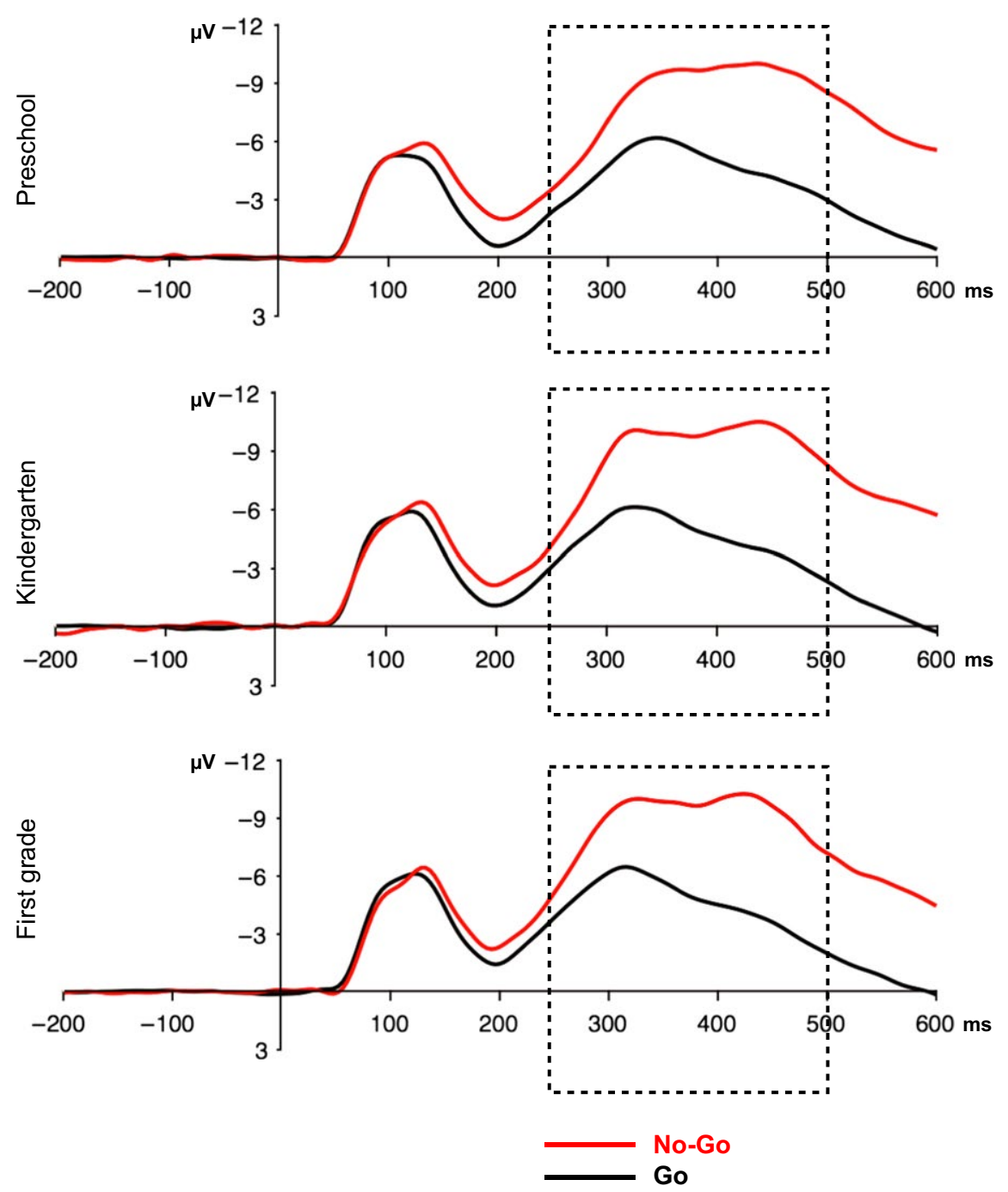

FIGURE 2 Right hemisphere ERPs averaged across frontal and central electrodes at each time point. By convention, negative is plotted upward. The neural index of conflict monitoring was operationalized as the $\mathrm{N} 2$ mean amplitude $(\mu \mathrm{V})$ difference between Go (black waveform) and No-Go (red waveform) conditions between 250 and 500 ms after stimulus onset. The No-Go N2 was larger (more negative in amplitude) than the Go N2 across time points 


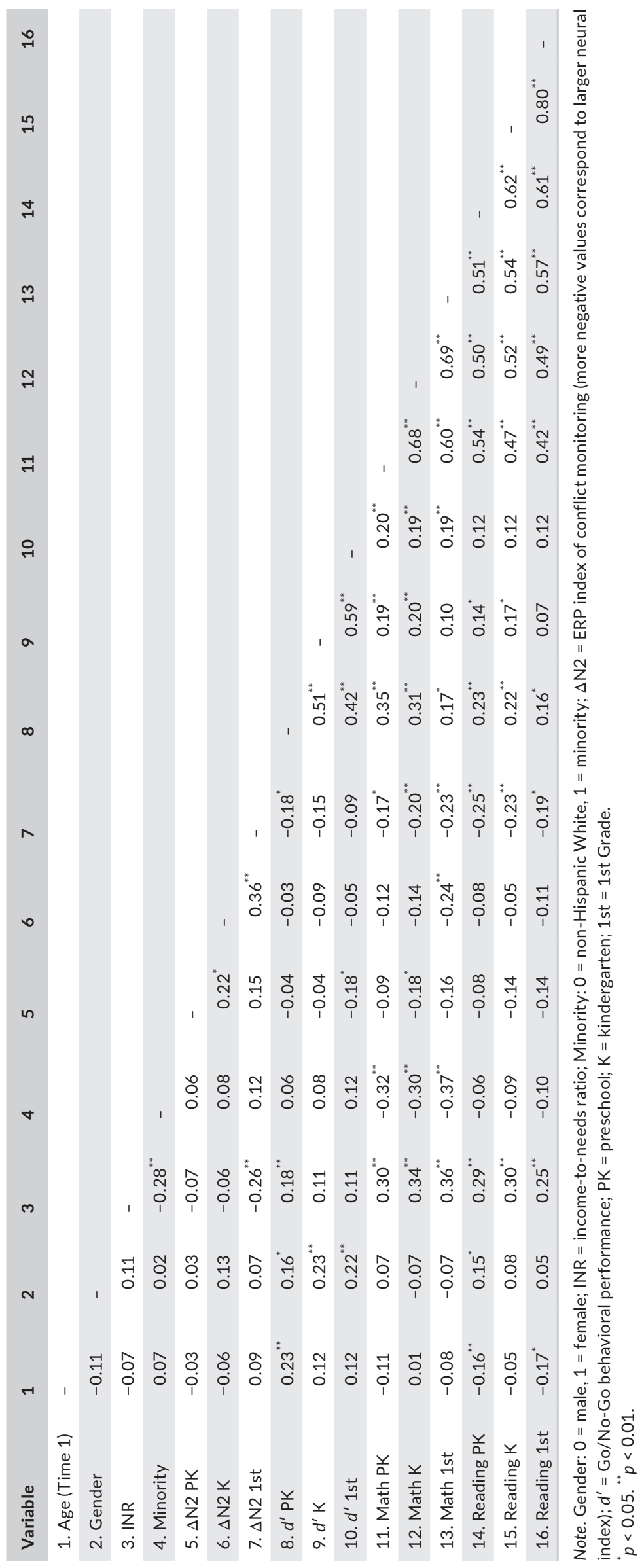


(i.e., $\Delta \mathrm{N} 2$ at time $t$ predicting $\Delta \mathrm{N} 2$ at time $t+1, d^{\prime}$ at time $t$ predicting $d^{\prime}$ at time $t+1$, and academic performance at time $t$ predicting academic performance at time $t+1$ ) and cross-lagged paths (i.e., $\Delta \mathrm{N} 2$ at time $t$ predicting $d^{\prime}$ and academic performance at time $t+1, d^{\prime}$ at time $t$ predicting $\Delta \mathrm{N} 2$ and academic performance at time $t+1$, and academic performance at time $t$ predicting $\Delta \mathrm{N} 2$ and $d^{\prime}$ at time $t+1$ ) between values of $\Delta \mathrm{N} 2, d^{\prime}$, and academic performance one time period apart. At each of the three time points, $\Delta N 2, d^{\prime}$, and academic performance were regressed on age at the first time point, minority status, and income-to-needs ratio. These covariates were included at each time point to eliminate confounding in each path between time-specific values of $\Delta \mathrm{N} 2$ and academic performance (e.g., Schmitt et al., 2017). In initial models, gender was also included as a covariate. Gender was only associated with $d^{\prime}$ in both models, and therefore only $d^{\prime}$ was regressed on gender in each model for parsimony. At each time point, the residual variance of $\Delta \mathrm{N} 2, d^{\prime}$, and academic performance were correlated (i.e., the residual variance of $\Delta \mathrm{N} 2$ at time $t$ was correlated with that of math performance at time $t$, etc.).

The cross-lagged model testing the longitudinal associations between $\Delta \mathrm{N} 2, d^{\prime}$, and math performance fit the data reasonably well, $\chi^{2}(15)=35.128, p=0.0024, \mathrm{CFI}=0.968$, RMSEA $=0.072$. This model is presented in Figure 3. For simplification, the effects of the control variables (age at first time of testing, gender, income-toneeds ratio, and minority status) were not presented in the figure, but reported in Supporting Information Table S5. The unstandardized coefficients, confidence intervals, and $p$ values are presented in Table 3. All autoregressive paths were significantly different from zero, with the neural indices of conflict monitoring, $d^{\prime}$, and math performance predicting themselves at the next time point. $d^{\prime}$ and math performance were correlated at preschool. This relationship faded by kindergarten and first grade. Of the cross-lagged paths, only those from the neural indices of conflict monitoring to subsequent values of math performance were significantly different from zero. Specifically, larger (more negative) $\Delta \mathrm{N} 2$ amplitudes at preschool were linked to higher levels of math performance at kindergarten and larger $\Delta \mathrm{N} 2$ amplitudes in kindergarten were linked to higher levels of math performance at first grade, after controlling for covariates as well as the previous year's math performance. However, math performance did not predict subsequent values of $\Delta \mathrm{N} 2$ at any time point. There were no cross-lagged effects from $d^{\prime}$ to or from conflict monitoring or math performance.

A parallel cross-lagged panel model was fit with $\Delta \mathrm{N} 2, d^{\prime}$, and, in place of math, reading performance. This model, which is illustrated in Figure 4, also fit the data reasonably well, $\chi^{2}(15)=34.445$, $p=0.003, \quad \mathrm{CFI}=0.970, \quad \mathrm{RMSEA}=0.070$. The unstandardized coefficients, confidence intervals, and $p$ values for this model are presented in Table 4. The covariate effects are reported in Supporting Information Table S6. As in the model for math, all autoregressive paths between consecutive measures of $\Delta \mathrm{N} 2, d^{\prime}$,

\begin{tabular}{|c|c|c|c|c|c|}
\hline \multirow[b]{2}{*}{ Path } & \multirow[b]{2}{*}{ Est. } & \multirow[b]{2}{*}{ SE } & \multicolumn{2}{|c|}{ Confidence interval } & \multirow[b]{2}{*}{$p$} \\
\hline & & & Lower & Upper & \\
\hline$\Delta \mathrm{N} 2 \mathrm{PK} \rightarrow \Delta \mathrm{N} 2 \mathrm{~K}$ & 0.188 & 0.076 & 0.040 & 0.336 & 0.013 \\
\hline$\Delta \mathrm{N} 2 \mathrm{~K} \rightarrow \Delta \mathrm{N} 21 \mathrm{st}$ & 0.302 & 0.070 & 0.165 & 0.439 & $<0.001$ \\
\hline$\Delta \mathrm{N} 2 \mathrm{PK} \rightarrow d^{\prime} \mathrm{K}$ & -0.010 & 0.016 & -0.041 & 0.022 & 0.550 \\
\hline$\Delta \mathrm{N} 2 \mathrm{~K} \rightarrow d^{\prime} 1 \mathrm{st}$ & -0.003 & 0.016 & -0.034 & 0.028 & 0.834 \\
\hline$\Delta \mathrm{N} 2 \mathrm{PK} \rightarrow$ Math K & -0.362 & 0.174 & -0.702 & -0.021 & 0.037 \\
\hline$\Delta \mathrm{N} 2 \mathrm{~K} \rightarrow$ Math 1st & -0.354 & 0.172 & -0.691 & -0.018 & 0.039 \\
\hline$d^{\prime} \mathrm{PK} \rightarrow \mathrm{d}^{\prime} \mathrm{K}$ & 0.456 & 0.058 & 0.342 & 0.569 & $<0.001$ \\
\hline$d^{\prime} \mathrm{K} \rightarrow d^{\prime} 1 \mathrm{st}$ & 0.530 & 0.058 & 0.417 & 0.643 & $<0.001$ \\
\hline$d^{\prime} \mathrm{PK} \rightarrow \Delta \mathrm{N} 2 \mathrm{~K}$ & 0.092 & 0.313 & -0.522 & 0.706 & 0.768 \\
\hline$d^{\prime} \mathrm{K} \rightarrow \Delta \mathrm{N} 2$ 1st & -0.401 & 0.279 & -0.948 & 0.058 & 0.151 \\
\hline$d^{\prime}$ PK $\rightarrow$ Math K & 0.496 & 0.646 & -0.770 & 1.559 & 0.442 \\
\hline$d^{\prime} \mathrm{K} \rightarrow$ Math 1st & -0.610 & 0.614 & -1.813 & 0.400 & 0.320 \\
\hline Math PK $\rightarrow$ Math K & 0.595 & 0.055 & 0.488 & 0.702 & $<0.001$ \\
\hline Math $\mathrm{K} \rightarrow$ Math 1st & 0.585 & 0.054 & 0.479 & 0.691 & $<0.001$ \\
\hline Math $\mathrm{PK} \rightarrow \Delta \mathrm{N} 2 \mathrm{~K}$ & -0.038 & 0.028 & -0.093 & 0.017 & 0.178 \\
\hline Math $\mathrm{K} \rightarrow \Delta \mathrm{N} 2$ 1st & -0.006 & 0.025 & -0.055 & 0.042 & 0.793 \\
\hline Math PK $\rightarrow d^{\prime} \mathrm{K}$ & -0.002 & 0.005 & -0.012 & 0.007 & 0.652 \\
\hline Math $\mathrm{K} \rightarrow d^{\prime}$ 1st & 0.006 & 0.005 & -0.004 & 0.015 & 0.251 \\
\hline
\end{tabular}

TABLE 3 Direct associations from the autoregressive cross-lagged model for math performance

Note. Est.: unstandardized estimate; INR: income-to-needs ratio; $\Delta \mathrm{N} 2$ : ERP index of conflict monitoring (mean amplitude of the right hemisphere N2 difference wave), more negative values correspond to larger neural index; $d$ ': Go/No-Go behavioral performance; Math: Woodcock-Johnson Applied Problems Standard Scores. 
TAB LE 4 Direct associations from the autoregressive crosslagged model for reading performance

\begin{tabular}{|c|c|c|c|c|c|}
\hline \multirow[b]{2}{*}{ Path } & \multirow[b]{2}{*}{ Est. } & \multirow[b]{2}{*}{ SE } & \multicolumn{2}{|c|}{$\begin{array}{l}\text { Confidence } \\
\text { interval }\end{array}$} & \multirow[b]{2}{*}{$p$} \\
\hline & & & Lower & Upper & \\
\hline $\begin{array}{c}\Delta \mathrm{N} 2 \mathrm{PK} \\
\Delta \mathrm{N} 2 \mathrm{~K}\end{array}$ & 0.190 & 0.076 & 0.042 & 0.338 & 0.012 \\
\hline $\begin{array}{r}\Delta \mathrm{N} 2 \mathrm{~K} \rightarrow \\
\Delta \mathrm{N} 21 \mathrm{st}\end{array}$ & 0.294 & 0.069 & 0.159 & 0.429 & $<0.001$ \\
\hline $\begin{array}{l}\Delta \mathrm{N} 2 \mathrm{PK} \rightarrow \\
\mathrm{d}^{\prime} \mathrm{K}\end{array}$ & -0.010 & 0.016 & -0.042 & 0.022 & 0.537 \\
\hline $\begin{array}{c}\Delta \mathrm{N} 2 \mathrm{~K} \rightarrow \\
d^{\prime} 1 \mathrm{st}\end{array}$ & -0.004 & 0.016 & -0.034 & 0.027 & 0.816 \\
\hline $\begin{array}{l}\Delta \mathrm{N} 2 \mathrm{PK} \rightarrow \\
\text { Reading K }\end{array}$ & -0.264 & 0.225 & -0.705 & 0.177 & 0.240 \\
\hline $\begin{array}{l}\Delta \mathrm{N} 2 \mathrm{~K} \rightarrow \\
\text { Reading 1st }\end{array}$ & -0.152 & 0.177 & -0.499 & 0.139 & 0.389 \\
\hline$d^{\prime} \mathrm{PK} \rightarrow \mathrm{d}^{\prime} \mathrm{K}$ & 0.446 & 0.056 & 0.335 & 0.556 & $<0.001$ \\
\hline$d^{\prime} \mathrm{K} \rightarrow d^{\prime} 1 \mathrm{st}$ & 0.542 & 0.058 & 0.429 & 0.654 & $<0.001$ \\
\hline $\begin{array}{r}d^{\prime} \mathrm{PK} \rightarrow \\
\Delta \mathrm{N} 2 \mathrm{~K}\end{array}$ & 0.031 & 0.304 & -0.566 & 0.627 & 0.920 \\
\hline $\begin{array}{l}d^{\prime} \mathrm{K} \rightarrow \\
\quad \Delta \mathrm{N} 2 \text { 1st }\end{array}$ & -0.317 & 0.279 & -0.864 & 0.230 & 0.256 \\
\hline $\begin{array}{l}d^{\prime} \text { PK } \rightarrow \\
\text { Reading K }\end{array}$ & 1.047 & 0.825 & -0.569 & 2.664 & 0.204 \\
\hline $\begin{array}{l}d^{\prime} \mathrm{K} \rightarrow \\
\quad \text { Reading 1st }\end{array}$ & -0.584 & 0.587 & -1.735 & 0.382 & 0.320 \\
\hline $\begin{array}{l}\text { Reading PK } \rightarrow \\
\text { Reading K }\end{array}$ & 0.709 & 0.069 & 0.573 & 0.845 & $<0.001$ \\
\hline $\begin{array}{l}\text { Reading } \mathrm{K} \rightarrow \\
\text { Reading 1st }\end{array}$ & 0.693 & 0.037 & 0.620 & 0.766 & $<0.001$ \\
\hline $\begin{array}{l}\text { Reading PK } \rightarrow \\
\Delta \mathrm{N} 2 \mathrm{~K}\end{array}$ & -0.026 & 0.024 & -0.074 & 0.021 & 0.281 \\
\hline $\begin{array}{c}\text { Reading } \mathrm{K} \rightarrow \\
\Delta \mathrm{N} 2 \text { 1st }\end{array}$ & -0.024 & 0.016 & -0.055 & 0.007 & 0.127 \\
\hline $\begin{array}{l}\text { Reading PK } \rightarrow \\
d^{\prime} \mathrm{K}\end{array}$ & 0.000 & 0.005 & -0.009 & 0.009 & 0.948 \\
\hline $\begin{array}{l}\text { Reading } \mathrm{K} \rightarrow \\
d^{\prime} \text { 1st }\end{array}$ & 0.000 & 0.004 & -0.006 & 0.007 & 0.907 \\
\hline
\end{tabular}

Note. Est.: unstandardized estimate; INR: income-to-needs ratio; $\Delta \mathrm{N} 2$ : ERP index of conflict monitoring (mean amplitude of the right hemisphere N2 difference wave); $d^{\prime}$ : Go/No-Go behavioral performance; Reading: Woodcock-Johnson Letter Identification Standard Scores.

and reading performance were significantly different from zero, suggesting that each variable predicted itself at the next time point. Similar to the model with math performance, $d^{\prime}$ and reading performance were correlated at preschool, which also faded by kindergarten and first grade. Unlike in the model for math, in the model for reading performance, no cross-lagged paths were significantly different from zero, suggesting that changes in relative standing on $\Delta N 2, d^{\prime}$, and reading performance were unrelated across waves.

\section{4 | DISCUSSION}

The current study investigated the longitudinal associations between an ERP index of conflict monitoring, $\Delta \mathrm{N} 2$, and emergent academic skills from preschool through first grade. To do so, we first focused on delineating the longitudinal characteristics of $\Delta \mathrm{N} 2$ in a classic Go/No-Go task (i.e., frequent Go vs. infrequent No-Go trials) in our sample. The $\Delta \mathrm{N} 2$ index of conflict monitoring was observed over the right hemisphere electrodes and did not show change in amplitude or scalp distribution during this developmental period. These findings emphasized the importance of longitudinal designs in developmental ERP research. $\Delta \mathrm{N} 2$ had prospective links to later math skills, but not reading skills, which implied that the relationship between $\Delta \mathrm{N} 2$ and academic skills may be domain specific during the early years of elementary school. $\Delta \mathrm{N} 2$ explained unique variance in later math skills above and beyond the behavioral performance in the Go/No-Go task, suggesting that the neural index of conflict monitoring provided additional value in predicting early math performance. We did not find any support for the hypothesis that early math and reading skills contributed to later conflict monitoring.

\section{1 $\Delta$ N2 as an index of conflict monitoring}

The difference between the N2 amplitudes for frequent and infrequent response representations has been considered a neural index of conflict monitoring and has generally been observed as larger (more negative) N2 mean amplitude for the infrequent versus frequent responses (Donkers \& Van Boxtel, 2004; Randall \& Smith, 2011). In the present study, larger N2 mean amplitude for the infrequent (No-Go) versus frequent (Go) trials was observed as early as preschool years, suggesting that this neural index of conflict monitoring, denoted as $\Delta \mathrm{N} 2$, is already emergent in early childhood.

We observed this neural index of conflict monitoring (i.e., $\Delta \mathrm{N} 2$ as larger amplitude for No-Go vs. Go trials) only over the right hemisphere across time points. This result is consistent with the findings of several studies that examined the scalp distribution of $\mathrm{N} 2$ across hemispheres (Benikos \& Johnstone, 2009; Lahat et al., 2010; Smith et al., 2004). Several studies that assessed the N2 component using Go/No-Go tasks in developmental populations particularly focused on midline electrodes (Cragg et al., 2009; Lamm et al., 2006). Yet, if we had limited our ERP analyses of conflicting monitoring to the midline electrodes, we would not have found differences between the Go and No-Go N2 amplitudes and would have overlooked the presence of $\Delta \mathrm{N} 2$ over the right hemisphere electrodes. Thus, our findings emphasize the utility of investigating the scalp distribution of ERP components in developmental research.

In adults, the conflict monitoring system relies on functional interactions between the posterior medial frontal cortex, serving as an evaluative system to detect conflict, and the lateral prefrontal cortex, implementing performance adjustments (Ridderinkhof, Ullsperger, Crone, \& Nieuwenhuis, 2004). A meta-analysis of adult studies reported that the regions of the fronto-parietal control network, especially the right middle frontal gyrus and the right inferior 


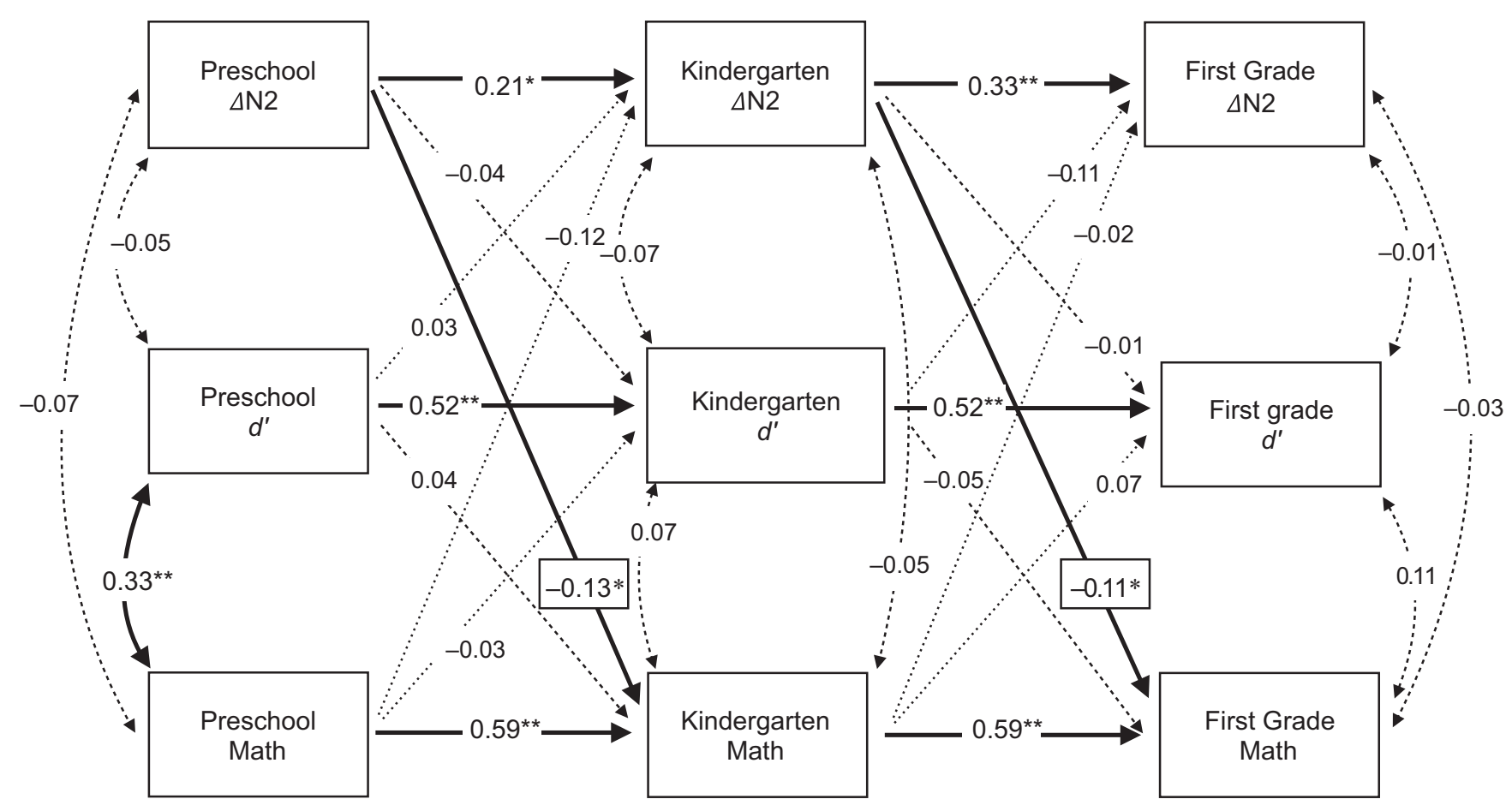

FIGURE 3 The cross-lagged model showing the longitudinal associations between the neural index of conflict monitoring ( $\Delta$ N2), Go/NoGo behavioral performance $\left(d^{\prime}\right)$, and math performance from preschool through first grade. Standardized coefficients are shown. Statistically significant paths are shown with solid lines, and nonsignificant paths are shown with dashed lines. ${ }^{*} p<0.05,{ }^{* *} p<0.01$

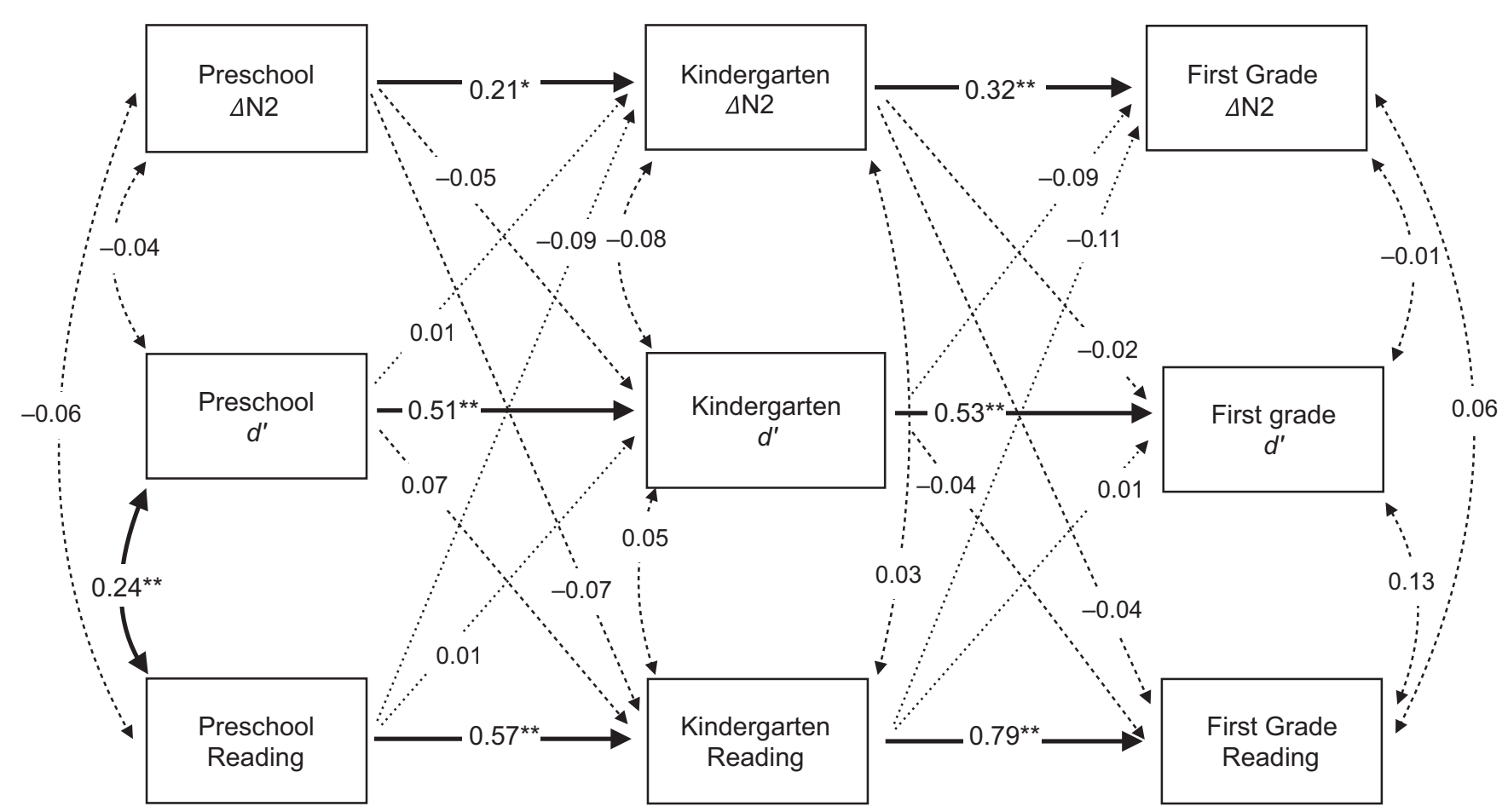

FIGURE 4 The cross-lagged model showing the longitudinal associations between the neural index of conflict monitoring ( $\Delta$ N2), Go/ No-Go behavioral performance $\left(d^{\prime}\right)$, and reading performance from preschool through first grade. Standardized coefficients are shown. Statistically significant paths are shown with solid lines, and nonsignificant paths are shown with dashed lines. ${ }^{*} p<0.05,{ }^{* *} p<0.01$ 
parietal cortex, were engaged in Go/No-Go tasks (Swick, Ashley, \& Turken, 2011). Although the low spatial resolution of ERPs precludes us from any conclusions about which brain regions underlie $\Delta \mathrm{N} 2$ in our study, the finding that the $\Delta \mathrm{N} 2$ was observed only over the right hemisphere electrodes may suggest the presence of a right-lateralized fronto-parietal network involved in conflict monitoring even before children start kindergarten.

Previous developmental Go/No-Go studies, which have predominantly used cross-sectional designs, have been inconsistent with regard to findings about N2 amplitude change with age, arguing for increase, decrease, or no change in amplitude (Cragg et al., 2009; Hoyniak, 2017; Johnstone et al., 2007). In our longitudinal study with relatively close time points, we did not find any evidence for developmental change in the amplitude or scalp distribution of the N2 component as children transitioned from preschool to early years of formal schooling. These findings emphasize the need for longitudinal designs in developmental ERP research. Contrary to our findings, in a recent study, increases in neural activation of right posterior parietal cortex were observed in a Go/No-Go task in children who were exposed to a year of formal schooling compared to kindergartners of similar age (Brod, Bunge, \& Shing, 2017). To speculate, the change in neural activity reported in this study may be related to a cognitive process other than conflict monitoring. Alternatively, the differences between findings across studies may result from disparities in task difficulty. For instance, in the study by Brod et al. (2017), average NoGo accuracy at kindergarten was much lower compared to what we observed. It remains an intriguing question to be addressed whether change in $\Delta \mathrm{N} 2$ might have been observed if we had used a different, more challenging Go/No-Go task during this developmental period.

It is also important to note that what we observed in this developmental period does not appear adult-like in comparison with previous research (e.g., Donkers \& Van Boxtel, 2004; Groom \& Cragg, 2015). In children, we observed N2 components that were more prolonged in latency, with more diffuse scalp distributions, compared to what was typically observed in adults (e.g., Falkenstein, Hoormann, \& Hohnsbein, 1999; Folstein \& Van Petten, 2008; Jonkman, 2006). Such morphology and distribution differences imply that as an index of conflict monitoring, $\Delta \mathrm{N} 2$ continues to change past the developmental period we examined in this study.

\section{2 | Longitudinal associations between $\Delta \mathrm{N} 2$ and emergent academic skills}

Using $\Delta \mathrm{N} 2$ as a neural index of conflict monitoring, we investigated the longitudinal associations between conflict monitoring, behavioral performance in the Go/No-Go task, and emergent math and reading skills from preschool through first grade. To do so, first, we evaluated the longitudinal stability of each construct. $\Delta \mathrm{N} 2$ and Go/ No-Go behavioral performance, as well as emergent math and reading skills, were predicted by themselves from the previous time point, demonstrating developmental continuity from preschool to kindergarten, and then to first grade. These findings suggest that emergent individual differences in $\Delta \mathrm{N} 2, \mathrm{Go} / \mathrm{No}-\mathrm{Go}$ behavioral performance, and academic skills somewhat persist over time during this developmental period. $\Delta \mathrm{N} 2$ had lower levels of stability over time compared to the other measures. Although this may reflect actually lower levels of developmental stability for neural indices compared to behavioral outcomes, it is also plausible that, as an ERP difference score, $\Delta \mathrm{N} 2$ was noisier compared to the behavioral measures we used, and thus showed relatively lower developmental stability.

Accounting for the longitudinal stability of our variables, we examined the associations between $\Delta \mathrm{N} 2$ and emergent math and reading skills in separate cross-lagged models. Our hypothesis that $\Delta \mathrm{N} 2$ would be associated with math performance was partially supported, as the associations between $\Delta \mathrm{N} 2$ and math performance were not concurrent, but prospective. Importantly, $\Delta \mathrm{N} 2$ had prospective associations with math performance at kindergarten and first grade, after taking into account the previous year's math performance. Specifically, larger $\Delta \mathrm{N} 2$ at preschool predicted higher kindergarten math performance, and larger $\Delta \mathrm{N} 2$ at kindergarten predicted higher first-grade math performance. These results provided support for the contribution of the conflict monitoring system to emergent math skills, especially as children transition kindergarten and first grade.

As children transition to school, their repertoire of math rules gradually expands. As prior rules become increasingly automatic due to more frequent rehearsal, the new rules compete with the previously acquired ones. The conflict monitoring system may be involved in the detection of such response conflicts between automatic responses driven by more practiced rules, and newer responses that are relevant for the task at hand but less rehearsed, and thus less potent. Children who have stronger neural mechanisms of conflict monitoring may be more adept at detecting such response conflicts, which may help them to solve math problems correctly and advance in math as they continue to learn new rules.

The finding that the neural index of conflict monitoring was not related to math skills at preschool, but prospectively predicted kindergarten and first-grade math implies that conflict monitoring is associated with more complex math skills. During preschool years, children typically develop more basic math skills such as distinguishing among quantities and acquiring numeral names (e.g., Krajewski \& Schneider, 2009; Purpura et al., 2013). It is possible that the execution of these skills relies less on a conflict monitoring system that detects stimulus or response selection conflicts. As children transition to kindergarten and first grade, they add more complex math skills to their toolbox, such as counting by fives, addition, subtraction, and solving story problems (e.g., Howell \& Kemp, 2010; Krajewski \& Schneider, 2009; Lyons, Price, Vaessen, Blomert, \& Ansari, 2014). Successful execution of these skills may rely more on conflict monitoring as children increasingly face the challenge of conflict between responses of previously acquired and more practiced rules versus the newer ones. The lack of associations between $\Delta \mathrm{N} 2$ and math skills at preschool, and the emergence of prospective associations at kindergarten and first grade remain an unresolved issue to be further investigated.

We did not find any concurrent or prospective associations between $\Delta \mathrm{N} 2$ and emergent reading skills. This finding suggested that 
the associations between conflict monitoring and academic skills were specific to math development as children transitioned from preschool to early years of formal schooling. Several studies reported similar findings, linking various cognitive control skills to math development, but not reading development, or reporting weaker associations between cognitive control skills and reading compared to math performance (Blair et al., 2015; Schmitt et al., 2017). It has been argued that compared to math skills, early reading skills may rely more heavily on rote memorization, and thus have weaker associations with cognitive control measures (Blair et al., 2015). Accordingly, it is plausible that conflict monitoring may not play a critical role on early reading development. Alternatively, the associations between conflict monitoring and reading may appear in a time period beyond what we studied. Conflict monitoring may not be involved in early skills such as phonemic awareness and orthographic learning, but may be involved in more complex reading skills. Becoming a skilled reader requires gaining background knowledge about what words can mean in specific contexts and the ability to make inferences, for example, understanding that "jam" in the sentence "Denise was stuck in a jam" refers to traffic jam and not the fruit preservative (Castles et al., 2018). Conflict monitoring may be more relevant as reading skills become more sophisticated, for example, when children need to forego the more familiar and automatic reading response (e.g., jam as fruit preservative) in service of the less frequent but relevant reading response (e.g., jam as traffic jam).

Another aim of the present study was to assess whether $\Delta \mathrm{N} 2$ provided any additional information above and beyond Go/No-Go behavioral performance in predicting emergent academic skills. Go/No-Go behavioral task performance was not associated with $\Delta \mathrm{N} 2$ at any time point. Some researchers found links between N2 amplitudes and task accuracy in Go/No-Go tasks (e.g., Cragg et al., 2009; Ruberry et al., 2017); however, others did not find any associations between N2 amplitudes and task accuracy (e.g., Lahat et al., 2010; Lamm et al., 2014). It has been demonstrated that task characteristics can modify behavioral and neural indices acquired in a Go/No-Go task. For instance, both the behavioral performance and the $\mathrm{N} 2$ amplitudes in Go/No-Go tasks are influenced by task difficulty (Benikos, Johnstone, \& Roodenrys, 2013). Given the overall high performance in our Go/No-Go task, which implied potential ceiling effects, the lack of associations between $\Delta \mathrm{N} 2$ and behavioral task performance was not surprising.

However, what we found surprising was that the behavioral performance in the Go/No-Go task was concurrently associated with math and reading performance at preschool. The Go/No-Go task is commonly referred to as a sustained attention to response or inhibitory control task (Cragg \& Nation, 2008; Manly, Robertson, Galloway, \& Hawkins, 1999). Successful performance on this task relies on various cognitive control skills, such as attentional control and working memory. To speculate, Go/No-Go behavioral performance might have tapped heavily into some cognitive control abilities, such as attentional control, that had shared variance with emergent math and reading skills, but was not indexed by $\Delta$ N2. Beyond preschool, Go/No-Go behavioral performance was not associated with either $\Delta \mathrm{N} 2$ or academic skills. This finding most likely resulted from the high accuracy we observed across the time points, suggesting potential ceiling effects in our Go/No-Go task. The use of a more challenging Go/No-Go task might have linked the overall behavioral performance in the Go/No-Go task to $\Delta \mathrm{N} 2$ and academic skills.

$\Delta \mathrm{N} 2$ was associated with the subsequent year's math performance above and beyond the behavioral performance during the $\mathrm{Go} /$ No-Go task. This finding suggested that the neural index of conflict monitoring provided added value in predicting emergent math skills. These results are consistent with previous research showing that neural activity accounted for unique variance in academic performance, above and beyond behavioral task performance alone (Dumontheil \& Klingberg, 2011; Hoeft et al., 2007; Peters et al., 2017). In line with these studies, our findings suggest that neural assessments can provide information that may not be captured by behavioral assessments alone. This may be particularly applicable for instances where behavioral task performance is fairly high among individuals. Especially in such cases, behavioral performance may not be as sensitive of an index to reflect individual differences, whereas neural indices may provide additional predictive information. Furthermore, neural indices, such as $\Delta N 2$, may be particularly useful for studying the unique contributions of cognitive faculties like conflict monitoring that may be hard to tease apart from overall behavioral performance.

In addition to assessing the prospective links from $\Delta \mathrm{N} 2$ to later math and reading performance, we also examined the prospective links from early academic skills to later $\Delta N 2$. Neither math nor reading skills predicted later $\Delta \mathrm{N} 2$. A few studies demonstrated bidirectional longitudinal associations between cognitive control and academic skills (Clements et al., 2016; Fuhs et al., 2014). However, we did not find any evidence for bidirectional relationships between conflict monitoring and math performance. One explanation can be that such reciprocity emerges as children proceed to learn newer and more complex rules in later years of elementary school. As children face response conflicts more frequently (e.g., proceeding to multiplication and division after addition and subtraction, or comprehending passages that include words with less frequently used meanings), they may have greater opportunities to practice their conflict monitoring skills. This may lead to the conflict monitoring system to be enhanced by increased math and reading practice, but potentially at a developmental period beyond what we examined in the current study, such as later in the elementary school.

\subsection{Limitations and Future Directions}

One limitation of our study is that we measured the neural index of conflict monitoring in a task with a fixed interstimulus interval. In a Go/No-Go task, especially with a fixed interstimulus interval, a preceding contingent negative variation (CNV) may distort the N2 component (Oddy, Barry, Johnstone, \& Clarke, 2005). CNV is observed during the interval between a warning stimulus and a subsequent stimulus that requires a response, and is considered an index of motor anticipation and preparation (Rohrbaugh, Syndulko, \& Lindsley, 1976; Walter, 1964). It has been argued that using difference waves can eliminate this problem as the overlapping electrophysiological activity from the previous time period 
would be the same for both conditions and be subtracted away with the creation of a difference wave (Luck, 2014). However, it remains a future direction to be pursued to what extent CNV is associated with N2 components in children and whether this neural index of anticipation and motor preparation would provide any additional predictive information for emergent academic skills.

Another limitation of our study is the missingness in the neural measures. Although our coverage rates were comparable to several longitudinal studies with only behavioral measures (e.g., Roberts \& Bryant, 2011; Schaeffer, Petras, lalongo, Poduska, \& Kellam, 2003), missingness was still greater for $\Delta \mathrm{N} 2$ across time points compared to the behavioral measures. Children for whom we had ERP data did not differ from children who had no usable ERP data in terms of demographics; yet, the greater missingness for our neural measure remains a limitation. This issue needs to be addressed with improvements in neural data acquisition and processing techniques, before cognitive neuroscience measures can be widely used to complement behavioral assessments in developmental and educational research.

Although our results demonstrated that the neural indices of conflict monitoring predicted math performance prospectively, the effects were small in magnitude. One possible explanation for such small effects is that conflict monitoring relates to specific math skills, but not others. The standardized math scores we used in this study capture general aspects of math performance but do not give information about performance in specific subcomponents. Studies that used more fine-grained math assessments revealed that particular cognitive control skills were related to specific aspects of math performance (Purpura et al., 2017). It is possible that conflict monitoring also relates to specific math skills and using a more general assessment might have obscured such associations. In addition, not all items on the Woodcock-Johnson Applied Problems would rely on conflict monitoring (e.g., counting fingers), and some aspects of math development that may rely on conflict monitoring (e.g., counting backward) are not captured by this task. Future research is needed to address this limitation of our study and assess whether the associations between conflict monitoring and math performance are particularly pertinent for certain math skills.

Furthermore, the reading assessment we used has been considered to tap into rote memorization skills rather than rely heavily on cognitive control processes (Blair et al., 2015). However, when children learn more sophisticated rules of reading, conflict monitoring may become more important in the execution of newer rules compared to the better rehearsed but irrelevant rules. Thus, different reading assessments may yield associations we did not find in our study. Another important future direction is the study of associations between conflict monitoring and reading skills in later years of elementary school.

\section{5 | CONCLUSION}

In summary, our study contributed to the characterization of a neural index of conflict monitoring, $\Delta \mathrm{N} 2$, in early childhood and provided initial evidence for prospective longitudinal associations between conflict monitoring and math performance as children transitioned from preschool to kindergarten and first grade. The lack of associations between conflict monitoring and reading implied that conflict monitoring is involved in academic skills in a domain-specific manner in early childhood. $\Delta \mathrm{N} 2$ predicted math performance above and beyond the behavioral performance in the Go/No-Go task, which suggested that a neural index can provide additional information in predicting math performance that is not captured by behavioral performance in a task.

The prospective associations between conflict monitoring and math performance, especially as children transition to formal schooling, lay the groundwork for investigating whether improving conflict monitoring skills can boost math performance during early school years. If such a directional association can be found experimentally, simple conflict monitoring activities could be incorporated into preschool and kindergarten math curriculum. In addition, the links between conflict monitoring and math performance suggest that some children may experience difficulty in monitoring response conflicts when they need to transition from using a more rehearsed but not relevant rule to a newer rule that is relevant for the task at hand. Identification of which children are at greater risk for such conflict monitoring difficulties can give educators greater precision to address children's obstacles as the math curriculum advances and as children need to select between multiple competing rules of math. Our findings highlight the need for future research on how conflict monitoring develops and contributes to academic skills in early childhood and beyond.

\section{ACKNOWLEDGMENTS}

This research was supported by Grant 5R01HD071957 from the Eunice Kennedy Shriver National Institute of Child Health and Human Development. The authors wish to express their thanks to the students and staff who assisted with data collection, the families who participated in the study, and Dr. Marion O'Brien who was instrumental in the planning and implementation of this study prior to her death.

\section{ENDNOTES}

${ }^{1}$ The correlations between the Go N2, No-Go N2, and outcome variables are reported in Supporting Information Table S3.

\section{ORCID}

Elif Isbell (iD https://orcid.org/0000-0002-4928-2438

Susan D. Calkins (iD https://orcid.org/0000-0001-7680-8266

Margaret M. Swingler (iD https://orcid.org/0000-0001-8627-2354

Esther M. Leerkes (iD https://orcid.org/0000-0002-8181-6452

\section{REFERENCES}

Benikos, N., \& Johnstone, S. J. (2009). Arousal-state modulation in children with AD/HD. Clinical Neurophysiology, 120(1), 30-40. https:// doi.org/10.1016/j.clinph.2008.09.026 
Benikos, N., Johnstone, S. J., \& Roodenrys, S. J. (2013). Varying task difficulty in the Go/Nogo task: The effects of inhibitory control, arousal, and perceived effort on ERP components. International Journal of Psychophysiology, 87(3), 262-272. https://doi.org/10.1016/j. ijpsycho.2012.08.005

Blair, C., \& Razza, R. P. (2007). Relating effortful control, executive function, and false belief understanding to emerging math and literacy ability in kindergarten. Child Development, 78(2), 647-663. https:// doi.org/10.1111/j.1467-8624.2007.01019.x

Blair, C., Ursache, A., Greenberg, M., \& Vernon-Feagans, L. (2015). Multiple aspects of self-regulation uniquely predict mathematics but not letter-word knowledge in the early elementary grades. Developmental Psychology, 51(4), 459. https://doi.org/10.1037/ a0038813.

Botvinick, M. M., Braver, T. S., Barch, D. M., Carter, C. S., \& Cohen, J. D. (2001). Conflict monitoring and cognitive control. Psychological Review, 108(3), 624. https://doi.org/10.1037/0033-295X.108.3.624

Botvinick, M. M., Cohen, J. D., \& Carter, C. S. (2004). Conflict monitoring and anterior cingulate cortex: An update. Trends in Cognitive Sciences, 8(12), 539-546. https://doi.org/10.1016/j.tics.2004.10.003

Brod, G., Bunge, S. A., \& Shing, Y. L. (2017). Does one year of schooling improve children's cognitive control and alter associated brain activation? Psychological Science, 28, 967-978. https://doi. org/10.1177/0956797617699838.

Bull, R., Espy, K. A., \& Wiebe, S. A. (2008). Short-term memory, working memory, and executive functioning in preschoolers: Longitudinal predictors of mathematical achievement at age 7 years. Developmental Neuropsychology, 33(3), 205-228. https://doi. org/10.1080/87565640801982312

Carter, C. S., \& van Veen, V. (2007). Anterior cingulate cortex and conflict detection: An update of theory and data. Cognitive, Affective, \& Behavioral Neuroscience, 7(4), 367-379. https://doi.org/10.3758/ CABN.7.4.367.

Castles, A., Rastle, K., \& Nation, K. (2018). Ending the reading wars: Reading acquisition from novice to expert. Psychological Science in the Public Interest, 19(1), 5-51. https://doi.org/10.1177/1529100618772271

Clements, D. H., Sarama, J., \& Germeroth, C. (2016). Learning executive function and early mathematics: Directions of causal relations. Early Childhood Research Quarterly, 36, 79-90. https://doi.org/10.1016/j. ecresq.2015.12.009

Cragg, L., Fox, A., Nation, K., Reid, C., \& Anderson, M. (2009). Neural correlates of successful and partial inhibitions in children: An ERP study. Developmental Psychobiology, 51(7), 533-543. https://doi. org/10.1002/dev.20391

Cragg, L., \& Nation, K. (2008). Go or no-go? Developmental improvements in the efficiency of response inhibition in midchildhood. Developmental Science, 11(6), 819-827. https://doi. org/10.1111/j.1467-7687.2008.00730.x.

Delorme, A., \& Makeig, S. (2004). EEGLAB: An open source toolbox for analysis of single-trial EEG dynamics including independent component analysis. Journal of Neuroscience Methods, 134(1), 9-21. https:// doi.org/10.1016/j.jneumeth.2003.10.009.

Donkers, F. C. L., \& Van Boxtel, G. J. M. (2004). The N2 in go/nogo tasks reflects conflict monitoring not response inhibition. Brain and Cognition, 56(2), 165-176. https://doi.org/10.1016/j. bandc.2004.04.005

Dumontheil, I., \& Klingberg, T. (2011). Brain activity during a visuospatial working memory task predicts arithmetical performance 2 years later. Cerebral Cortex, 22(5), 1078-1085. https://doi.org/10.1093/ cercor/bhr175

Duncan, G. J., Dowsett, C. J., Claessens, A., Magnuson, K., Huston, A. C., Klebanov, P., ... Japel, C. (2007). School readiness and later achievement. Developmental Psychology, 43(6), 1428-1446. https://doi. org/10.1037/0012-1649.43.6.1428.
Ehri, L. C. (2017). Orthographic mapping and literacy development revisited. In K. Cain, D. L. Compton, \& R. K. Parrila (Eds.), Theories of reading development (pp. 169-190). Amsterdam, the Netherlands: John Benjamins.

Enriquez-Geppert, S., Konrad, C., Pantev, C., \& Huster, R. J. (2010). Conflict and inhibition differentially affect the N200/P300 complex in a combined go/nogo and stop-signal task. Neurolmage, 51(2), 877-887. https://doi.org/10.1016/j.neuroimage.2010. 02.043.

Falkenstein, M., Hoormann, J., \& Hohnsbein, J. (1999). ERP components in go/nogo tasks and their relation to inhibition. Acta Psychologica, 101(2-3), 267-291. https://doi.org/10.1016/ S0001-6918(99)00008-6

Fisher, T., Aharon-Peretz, J., \& Pratt, H. (2011). Dis-regulation of response inhibition in adult attention deficit hyperactivity disorder (ADHD): An ERP study. Clinical Neurophysiology, 122(12), 2390-2399. https://doi.org/10.1016/j.clinph.2011.05.010

Folstein, J. R., \& Van Petten, C. (2008). Influence of cognitive control and mismatch on the N2 component of the ERP: A review. Psychophysiology, 45(1), 152-170.

Fuhs, M. W., Nesbitt, K. T., Farran, D. C., \& Dong, N. (2014). Longitudinal associations between executive functioning and academic skills across content areas. Developmental Psychology, 50(6), 1698. https:// doi.org/10.1037/a0036633

Groom, M. J., \& Cragg, L. (2015). Differential modulation of the N2 and P3 event-related potentials by response conflict and inhibition. Brain and Cognition, 97, 1-9. https://doi.org/10.1016/j. bandc.2015.04.004.

Hoeft, F., Ueno, T., Reiss, A. L., Meyler, A., Whitfield-Gabrieli, S., Glover, G. H., ... Jo, B. (2007). Prediction of children's reading skills using behavioral, functional, and structural neuroimaging measures. Behavioral Neuroscience, 121(3), 602. https://doi. org/10.1037/0735-7044.121.3.602

Howell, S. C., \& Kemp, C. R. (2010). Assessing preschool number sense: Skills demonstrated by children prior to school entry. Educational Psychology, 30(4), 411-429. https://doi. org/10.1080/01443411003695410

Hoyniak, C. (2017). Changes in the NoGo N2 event-related potential component across childhood: A systematic review and meta-analysis. Developmental Neuropsychology, 42(1), 1-24. https://doi.org/10.1 080/87565641.2016.1247162.

Johnstone, S. J., Dimoska, A., Smith, J. L., Barry, R. J., Pleffer, C. B., Chiswick, D., \& Clarke, A. R. (2007). The development of stop-signal and go/nogo response inhibition in children aged 7-12 years: Performance and event-related potential indices. International Journal of Psychophysiology, 63(1), 25-38.

Jonkman, L. M. (2006). The development of preparation, conflict monitoring and inhibition from early childhood to young adulthood: A Go/NoGo ERP study. Brain Research, 1097(1), 181-193. https://doi. org/10.1016/j.brainres.2006.04.064.

Jordan, N. C., Kaplan, D., Ramineni, C., \& Locuniak, M. N. (2009). Early math matters: Kindergarten number competence and later mathematics outcomes. Developmental Psychology, 45(3), 850. https://doi. org/10.1037/a0014939

Kenny, D. A. (1979). Correlation and causality. New York, NY: Wiley.

Kool, W., Shenhav, A., \& Botvinick, M. M. (2017). Cognitive control as cost-benefit decision making. In T. Egner (Ed.), The Wiley handbook of cognitive control (pp. 167-189). West Sussex, UK: John Wiley \& Sons.

Krajewski, K., \& Schneider, W. (2009). Early development of quantity to number-word linkage as a precursor of mathematical school achievement and mathematical difficulties: Findings from a four-year longitudinal study. Learning and Instruction, 19(6), 513-526. https://doi. org/10.1016/j.learninstruc.2008.10.002. 
Lahat, A., Todd, R. M., Mahy, C. E. V., Lau, K., \& Zelazo, P. D. (2010). Neurophysiological correlates of executive function: A comparison of European-Canadian and Chinese-Canadian 5-year-old children. Frontiers in Human Neuroscience, 3, 72. https://doi.org/10.3389/ neuro.09.072.2009.

Lamm, C., Walker, O. L., Degnan, K. A., Henderson, H. A., Pine, D. S., McDermott, J. M., \& Fox, N. A. (2014). Cognitive control moderates early childhood temperament in predicting social behavior in 7-yearold children: An ERP study. Developmental Science, 17(5), 667-681. https://doi.org/10.1111/desc.12158.

Lamm, C., Zelazo, P. D., \& Lewis, M. D. (2006). Neural correlates of cognitive control in childhood and adolescence: Disentangling the contributions of age and executive function. Neuropsychologia, 44(11), 2139-2148. https://doi.org/10.1016/j. neuropsychologia.2005.10.013.

Lo, S. L. (2018). A meta-analytic review of the event-related potentials (ERN and N2) in childhood and adolescence: Providing a developmental perspective on the conflict monitoring theory. Developmental Review, 48, 82-112. https://doi.org/10.1016/j.dr.2018.03.005

Lopez-Calderon, J., \& Luck, S. J. (2014). ERPLAB: An open-source toolbox for the analysis of event-related potentials. Frontiers in Human Neuroscience, 8, 213. https://doi.org/10.3389/fnhum.2014.00213.

Lucci, G., Berchicci, M., Perri, R. L., Spinelli, D., \& Di Russo, F. (2016). Effect of target probability on pre-stimulus brain activity. Neuroscience, 322, 121-128. https://doi.org/10.1016/j.neuroscience.2016.02.029.

Luck, S. J. (2014). An introduction to the event-related potential technique. Cambridge, MA: MIT Press.

Luck, S. J., \& Gaspelin, N. (2017). How to get statistically significant effects in any ERP experiment (and why you shouldn't). Psychophysiology, 54(1), 146-157.

Lyons, I. M., Price, G. R., Vaessen, A., Blomert, L., \& Ansari, D. (2014). Numerical predictors of arithmetic success in grades 1-6. Developmental Science, 17(5), 714-726. https://doi.org/10.1111/ desc.12152

Manly, T., Robertson, I. H., Galloway, M., \& Hawkins, K. (1999). The absent mind: Further investigations of sustained attention to response. Neuropsychologia, 37(6), 661-670. https://doi.org/10.1016/ S0028-3932(98)00127-4

Muthén, L. K., \& Muthén, B. O. (1998-2017). Mplus User's Guide (8th ed.). Los Angeles, CA: Muthén \& Muthén.

Nieuwenhuis, S., Yeung, N., van den Wildenberg, W., \& Ridderinkhof, K. R. (2004). Electrophysiological correlates of anterior cingulate function in a go/no-go task: Effects of response conflict and trial type frequency. Cognitive, Affective \& Behavioral Neuroscience, 3(1), 17-26. https://doi.org/10.3758/CABN.3.1.17

Oddy, B. W., Barry, R. J., Johnstone, S. J., \& Clarke, A. R. (2005). Removal of CNV effects from the N2 and P3 ERP components in a visual Go/ NoGo task. Journal of Psychophysiology, 19(1), 24-34. https://doi. org/10.1027/0269-8803.19.1.24.

Peters, S., Van der Meulen, M., Zanolie, K., \& Crone, E. A. (2017). Predicting reading and mathematics from neural activity for feedback learning. Developmental Psychology, 53(1), 149. https://doi. org/10.1037/dev0000234

Purpura, D. J., Baroody, A. J., \& Lonigan, C. J. (2013). The transition from informal to formal mathematical knowledge: Mediation by numeral knowledge. Journal of Educational Psychology, 105(2), 453. https:// doi.org/10.1037/a0031753

Purpura, D. J., Schmitt, S. A., \& Ganley, C. M. (2017). Foundations of mathematics and literacy: The role of executive functioning components. Journal of Experimental Child Psychology, 153, 15-34. https:// doi.org/10.1016/j.jecp.2016.08.010.

Randall, W. M., \& Smith, J. L. (2011). Conflict and inhibition in the cued-Go/NoGo task. Clinical Neurophysiology, 122(12), 2400-2407. https://doi.org/10.1016/j.clinph.2011.05.012.
Ridderinkhof, K. R., Ullsperger, M., Crone, E. A., \& Nieuwenhuis, S. (2004). The role of the medial frontal cortex in cognitive control. Science, 306(5695), 443-447.

Roberts, G., \& Bryant, D. (2011). Early mathematics achievement trajectories: English-language learner and native English-speaker estimates, using the early childhood longitudinal survey. Developmental Psychology, 47(4), 916. https://doi.org/10.1037/a0023865

Rohrbaugh, J. W., Syndulko, K., \& Lindsley, D. B. (1976). Brain wave components of the contingent negative variation in humans. Science, 191(4231), 1055-1057.

Ruberry, E. J., Lengua, L. J., Crocker, L. H., Bruce, J., Upshaw, M. B., \& Sommerville, J. A. (2017). Income, neural executive processes, and preschool children's executive control. Development and Psychopathology, 29(1), 143-154. https://doi.org/10.1017/ S095457941600002X

Schaeffer, C. M., Petras, H., lalongo, N., Poduska, J., \& Kellam, S. (2003). Modeling growth in boys' aggressive behavior across elementary school: Links to later criminal involvement, conduct disorder, and antisocial personality disorder. Developmental Psychology, 39(6), 1020. https://doi.org/10.1037/0012-1649.39.6.1020

Schmitt, S. A., Geldhof, G. J., Purpura, D. J., Duncan, R., \& McClelland, M. M. (2017). Examining the relations between executive function, math, and literacy during the transition to kindergarten: A multianalytic approach. Journal of Educational Psychology, 109(8), 1120. https://doi.org/10.1037/edu0000193

Selig, J. P., \& Little, T. D. (2012). Autoregressive and cross-lagged panel analysis for longitudinal data. In B. Laursen, T. D. Little, \& N. A. Card, (Eds.), Handbook of developmental research methods (pp. 265-278). New York, NY: Guilford Press.

Shahaf, G., Fisher, T., Aharon-Peretz, J., \& Pratt, H. (2015). Comprehensive analysis suggests simple processes underlying EEG/ ERP-demonstration with the go/no-go paradigm in ADHD. Journal of Neuroscience Methods, 239, 183-193. https://doi.org/10.1016/j. jneumeth.2014.10.016

Smith, J. L., Johnstone, S. J., \& Barry, R. J. (2004). Inhibitory processing during the go/nogo task: An ERP analysis of children with attentiondeficit/hyperactivity disorder. Clinical Neurophysiology, 115(6), 13201331. https://doi.org/10.1016/j.clinph.2003.12.027

Stanislaw, H., \& Todorov, N. (1999). Calculation of signal detection theory measures. Behavior Research Methods, Instruments, \& Computers, 31(1), 137-149. https://doi.org/10.3758/BF03207704

Swick, D., Ashley, V., \& Turken, U. (2011). Are the neural correlates of stopping and not going identical? Quantitative meta-analysis of two response inhibition tasks. Neurolmage, 56(3), 1655-1665. https://doi. org/10.1016/j.neuroimage.2011.02.070.

Tabachnick, B. G., \& Fidell, L. S. (2007). Using multivariate statistics. Boston, MA: Pearson/Allyn \& Bacon.

U.S. Census Bureau. (2010). Profile of General Population and Housing Characteristics. Retrieved from https://factfinder. census.gov/faces/tableservices/jsf/pages/productview. xhtml?pxml:id=DEC_10_SF1_SF1DP1\&prodType=table.

Vanderwert, R. E., Zeanah, C. H., Fox, N. A., \& Nelson, C. A. (2016). Normalization of EEG activity among previously institutionalized children placed into foster care: A 12-year follow-up of the Bucharest Early Intervention Project. Developmental Cognitive Neuroscience, 17, 68-75. https://doi.org/10.1016/j.dcn.2015.12.004.

Walter, W. G. (1964). Contingent negative variation: An electric sign of sensori-motor association and expectancy in the human brain. Nature, 230, 380-384. https://doi.org/10.1038/203380a0

Watts, T. W., Duncan, G. J., Chen, M., Claessens, A., Davis-Kean, P. E., Duckworth, K., ... Susperreguy, M. I. (2015). The role of mediators in the development of longitudinal mathematics achievement associations. Child Development, 86(6), 1892-1907. https://doi.org/10.1111/ cdev.12416. 
Woodcock, R. W., McGrew, K. S., \& Mather, N. (2001). Woodcock-Johnson III. Ithasca, IL: Riverside Publishing.

\section{SUPPORTING INFORMATION}

Additional supporting information may be found online in the Supporting Information section at the end of the article.
How to cite this article: Isbell E, Calkins SD, Cole VT, Swingler MM, Leerkes EM. Longitudinal associations between conflict monitoring and emergent academic skills: An event-related potentials study. Developmental Psychobiology. 2019;61:495-

512. https://doi.org/10.1002/dev.21809 